Historic, Archive Document

Do not assume content reflects current scientific knowledge, policies, or practices. 



\section{The Mastadon Everbearing Strawberry}

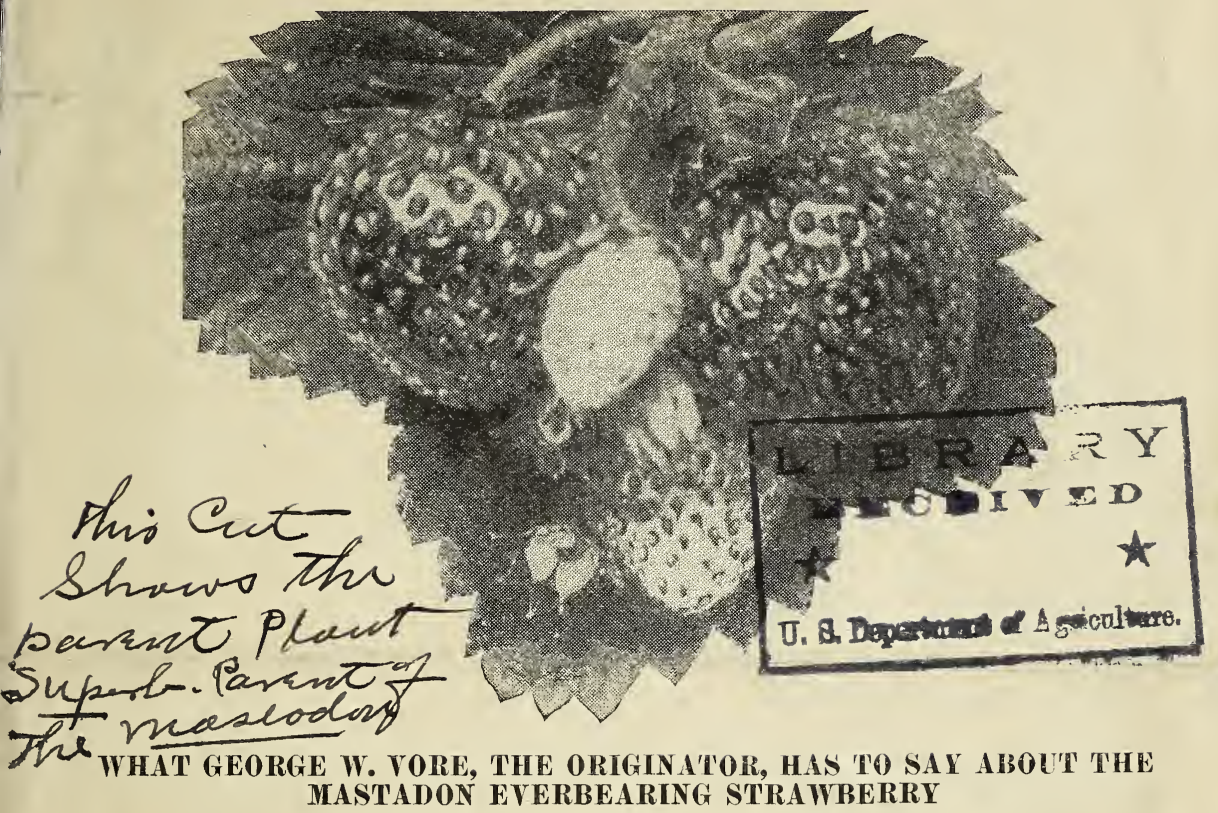

I planted the seed from a late June strawberry that had been fertilized by superb Everbearing Strawberry, in the year 1917. I got twenty seedlings. I selected one plant out of the twenty. All the others were worthless. I set this one plant in the spring of 1918, from which I got thirty-four plants.

During the following season, from those thirty-four plants, I picked twenty quarts of fine berries. From those thirty-four plants I set, the next spring, year 1919, 1,500 plants. I grew them for market. I have been growing strawberries for thirty-five years, but never grew any that came any ways near bearing as profitably or as good in quality as the Mastadon. They are very large and unexcelled in quality.

I have now one acre of these berries fruiting and I have made a careful estimate as to what can be done in the way of profits from one acre of ground under favorable conditions. I am safe in saying that I could pick three 24-quart crates every other day. Now you have one hundred and five days to pick. That will give you 31524 -quart crates from one acre of ground. I will put the price very low, say $\$ 4.00$ per crate, giving you $\$ 1,260$ from an acre of ground.

In cool weather I honestly believe you could ship them across the United States. I never had plants to grow as large or have as heavy roots. I declare they are simply wonderful. If you please plant a dozen of these plants you will get that many quarts and enough runners to plant a nice patch of them the next spring.

The last berries I picked this year was on the 3rd of January, 1922. GEORGE W. VORE 


\section{TESTIMONIALS}

The Mastadon is the finest strdwberry we ever used for our soda fountain trade. They are a very large and of a uniform sized berry, and of a very rich and lucious flavor.

With the Mastadon we were able to serve fresh crushed strawberries from the beginning to the closing of the fountain season.

Every fountain owner will find is to his advantage to use these fine berries as they are a sure business getter. Try them and be convinced.

\section{PEOPLES DRUG STORE}

Bunker Hill, Ind.

A. T. Teeter, Owner.

The Mastadon strawberry, originated and grown by George Vore, is one of, if not the finest berries we have. In size it is extremely nice for the table, and has a most palatable flavor. These berries can be picked from one freeze to the next, or during the entire summer from early in spring to late fall. The plant is a thrifty one, bearing large numbers throughout the season. For one wishing the best, should not fail to investigate or see this great plant.

\section{FRED FREEMAN \\ Bunker Hill, Indiana}

We have found the Mastadon strawberry much superior to any other. Has a much richer, red color, and finer flavor. Also jells more readily. Bears continuonsly through summer and fall months, until frozen.

MRS. EDNA WRIGHTS,

R. R. No. 8, Peru, Ind.

I have found the Mastadon strawberry to be very prolific, of good size and very fine flavored. Mr. Vore had berries from May till November in 1921.

MRS. CHARLES ZELL

Bunker Hill, Indiana.

I consider the Mastadon Everbearing Strawberry the hardiest, most vigorous and prolific strawberry that grows. The berries are large, sweet and of uniform size. Begins to bear in May and is continuous bearer till the ground freezes solid.

\section{MARION MCDOWELL}

Onward, Indiana,

We want our customers to try a few of these plants. Give them a fair trial. If you don't want more, then half a dozen, follow our instructions which will go with each shipment, and the one that reports the best success will receive a liberal reward. We believe that this is the biggest money making strawberry that has ever been discovered and for quality it hos he have harl but little success. with everbearing strawberries. As a rule they run very uneven in size. The Mastadon is very large and runs even in size and with that excellent flavor it brings the highest price in the market. Has sold for $\$ 1.00$ per quart. We think enough of this new berry that we will plant heavy of it this spring.

\section{THE EVERGREEN FRUIT FARM}

D. H. Flory, Prop.

LORI NSPORT, IXIIINI

Price $\$ 1.00$ per dozen. Not more than fity plants sold to any one person. 